\title{
MEDIDAS DE BIOSSEGURANÇA \\ NA ASSISTÊNCIA DE ENFERMAGEM A PACIENTES HEMODIALÍTICOS: REVISÃO INTEGRATIVA
}

\author{
BIOSAFETY MEASURES IN NURSING \\ CARE TO HEMODIALYSIS PATIENTS: \\ INTEGRATIVE REVIEW
}

\section{MEDIDAS DE BIOSEGURIDAD EN LA ATENCIÓN DE ENFERMERÍA A PACIENTES EN HEMODIÁLISIS: REVISIÓN INTEGRADORA}

\author{
Gilberto dos Santos Dias de Souza ${ }^{1}$ \\ Hercules Pereira Coelho ${ }^{2}$ \\ Janayle Kéllen Duarte de Sales ${ }^{3}$ \\ Halana Cecília Vieira Pereira ${ }^{4}$ \\ Ana Maria Machado Borges ${ }^{5}$ \\ Aline Morais Venancio de Alencar ${ }^{6}$
}

Como citar este artigo: Souza GSD, Coelho HP, Sales JKD, Pereira HCV, Borges AMM, Alencar AMV. Medidas de biossegurança na assistência de enfermagem a pacientes hemodialíticos: revisão integrativa. Rev baiana enferm. 2022;36:e38203.

Objetivo: compreender o conhecimento dos profissionais de enfermagem acerca das medidas de biossegurança na prevenção de agravos à saúde durante a assistência em hemodiálise. Método: revisão integrativa da literatura realizada nas bases de dados da LILACS e BDENF e no diretório de revistas da SciELO. Foram identificadas 691 obras. Após aplicados os critérios de inclusão e exclusão, a amostra final foi composta por 12 artigos. Resultados: os profissionais de enfermagem aderem parcialmente às medidas de biossegurança e compreendem sua necessidade, assim como detêm conhecimento sobre a temática, muito embora esse mesmo conhecimento não tenha sido aplicado em sua totalidade na assistência. Conclusão: os profissionais detêm conhecimento acerca das medidas de biossegurança e reconhecem a necessidade da sua aplicação como instrumento efetivo no desempenho das suas atividades laborais, adotando e recomendando a sua utilização. No entanto, existem lacunas do conhecimento entre o discurso e a prática assistencial.

Descritores: Enfermagem. Hemodiálise. Riscos Ocupacionais. Prevenção de Acidentes. Contenção de Riscos Biológicos.

\footnotetext{
Enfermeiro. Enfermeiro do Trabalho no Hospital Maternidade São Vicente de Paulo. Barbalha, Ceará, Brasil. https://orcid.org/0000-000 I-7460-5297.

Enfermeiro. Universidade Regional do Cariri. Bolsista da Coordenação de Aperfeiçoamento de Pessoal de Nível Superior. Crato, Ceará, Brasil. herculesleon_0I@yahoo.com. https://orcid.org/0000-000I-6420-7527.

Enfermeira. Universidade Regional do Cariri. Bolsista da Fundação Cearense de Apoio ao Desenvolvimento Científico e Tecnológico. Crato, Ceará, Brasil. https:// orcid.org/0000-0003-0894-2070.

4 Enfermeira. Mestre em Ciências da Educação. Professora no Centro Universitário Doutor Leão Sampaio. Juazeiro do Norte, Ceará, Brasil. https://orcid.org/00000001-8049-1994.

5 Enfermeira. Mestre em Ciências da Saúde. Professora no Centro Universitário Doutor Leão Sampaio. Juazeiro do Norte, Ceará, Brasil. https://orcid.org/0000-00026348-0772.

6 Enfermeira. Preceptora e professora no Centro Universitário Doutor Leão Sampaio. Juazeiro do Norte, Ceará, Brasil. https://orcid.org/0000-000 I-9249-949I.
} 
Objective: to understand the knowledge of nursing professionals about biosafety measures in the prevention of health problems during hemodialysis care. Method: integrative review of the literature performed in LILACS and BDENF databases and in the directory of SciELO journals. 691 works were identified. After the inclusion and exclusion criteria were applied, the final sample consisted of 12 articles. Results: nursing professionals partially adhere to biosafety measures and understand their need, as well as have knowledge about the theme, even though this same knowledge has not been applied in its entirety in care. Conclusion: professionals have knowledge about biosafety measures and recognize the need for their application as an effective instrument in the performance of their work activities, adopting and recommending their use. However, there are gaps in knowledge between discourse and care practice.

Descriptors: Nursing. Hemodialysis. Occupational Risks. Accident Prevention. Containment of Biological Risks.

Objetivo: comprender el conocimiento de los profesionales de enfermería sobre las medidas de bioseguridad en la prevención de problemas de salud durante el cuidado de la bemodiálisis. Método: revisión integradora de la literatura realizada en bases de datos LILACS y BDENF y en el directorio de revistas SciELO. Se identificaron 691 obras. Después de aplicar los criterios de inclusión y exclusión, la muestra final consistió en 12 artículos. Resultados: los profesionales de enfermería se adbieren parcialmente a las medidas de bioseguridad y comprenden su necesidad, así como tienen conocimiento sobre el tema, a pesar de que este mismo conocimiento no se ha aplicado en su totalidad en el cuidado. Conclusión: los profesionales tienen conocimientos sobre las medidas de bioseguridad y reconocen la necesidad de su aplicación como un instrumento eficaz en el desempeño de sus actividades laborales, adoptando y recomendando su uso. Sin embargo, existen brechas en el conocimiento entre el discurso y la práctica del cuidado.

Descriptores: Enfermería. Hemodiálisis. Riesgos Laborales. Prevención de Accidentes. Contención de Riesgos Biológicos.

\section{Introdução}

A hemodiálise é um procedimento clínico utilizado no processo de filtragem sanguínea, realizada quando há uma disfunção orgânica que impossibilita a filtração pelo sistema renal, ao qual é atribuído, dentre outras funções, da filtragem e excreção de substâncias, que, quando em excesso, são prejudiciais ao organismo, tais como: ureia, ácido úrico, creatinina, potássio, sódio e outros ${ }^{(1)}$.

A assistência em saúde ao paciente hemodialítico, portador de Insuficiência Renal Crônica (IRC), é respaldada pela Portaria n. 3.415, do Ministério da Saúde (MS), de 22 de outubro de 2018, que estabelece normas e diretrizes para adequação dos estabelecimentos e/ou centros de especialidades em saúde, para realização do procedimento de hemodiálise ${ }^{(2)}$.

Entende-se por biossegurança o conjunto de ações que vislumbram a minimização de riscos e/ou a prevenção de eventos adversos, que possam comprometer a saúde dos profissionais e/ou dos usuários. As medidas de biossegurança são elaboradas por meio do desenvolvimento de pesquisas científicas, testes e aprimoramentos técnicos, os quais buscam qualificar técnicas e procedimentos, com o intuito de maximizar a qualidade da assistência e a segurança do profissional durante a realização de procedimentos ${ }^{(3)}$.

Estudo realizado em um serviço de hemodiálise de uma instituição privada intra-hospitalar, conveniada ao Sistema Único de Saúde (SUS), no sul do Brasil, com 46 trabalhadores de enfermagem, evidenciou, em meio aos seus resultados, a ocorrência de acidentes de trabalho em $17,4 \%$ destes $^{(4)}$.

Em virtude do contato intrínseco com o paciente, no que tange à assistência em saúde, os profissionais de enfermagem estão, comumente, expostos a inúmeros riscos de infecções por patógenos, os quais se tornam mais evidentes quando não são respeitadas às normas e diretrizes de biossegurança, conforme estabelecido na Norma Regulamentadora 32 (NR-32), do Ministério do Trabalho e Emprego, que dispõe da segurança e saúde no trabalho em serviços de saúde ${ }^{(5)}$.

No que concerne ao tratamento de pacientes hemodialíticos, os profissionais de enfermagem 
encontram-se constantemente expostos a riscos de contaminação por aerossóis e fluidos secretivos, além do próprio acidente de trabalho por manipulação de equipamentos perfurocortantes e materiais contaminados, sendo estes elencados como riscos ocupacionais ${ }^{(6)}$.

Justifica-se a realização deste estudo devido à baixa adesão dos profissionais de enfermagem às medidas de biossegurança no âmbito assistencial, haja vista que, embora cursem disciplinas que abordam essa temática durante os diversos cursos de graduação em saúde, poucos detêm e/ou aplicam tal conhecimento na sua totalidade na prática assistencial, aspectos estes observados pelo pesquisador em meio aos estágios curriculares em enfermagem.

Assim, o estudo torna-se relevante para a promoção de discussões construtivas no âmbito da saúde, frente às medidas de biossegurança no ambiente laboral dos estabelecimentos de saúde que atuam na realização de hemodiálise, haja vista os riscos inerentes às atividades dos profissionais, devendo esta temática ser debatida e desenvolvida, em especial, com a equipe de enfermagem, por ser a maior categoria profissional, bem como os que assistem de maneira direta e contínua os pacientes.

Nesse contexto, o estudo objetivou compreender o conhecimento dos profissionais de enfermagem acerca das medidas de biossegurança na prevenção de agravos à saúde durante a assistência em hemodiálise.

\section{Método}

Trata-se de revisão integrativa da literatura, com enfoque descritivo, acerca das medidas de biossegurança na assistência de enfermagem a pacientes hemodialíticos.

A revisão integrativa é uma ferramenta e/ou método científico que vislumbra substanciar o conhecimento acerca de uma área específica, mediante um processo sistemático e fundamentado cientificamente ${ }^{(7)}$.

Para realizar este tipo de estudo é necessária a observância a seis passos, a saber: elaboração da questão norteadora do estudo, busca e seleção dos estudos, recolhimento de dados da investigação, avaliação crítica dos achados, síntese dos resultados e apresentação do método ${ }^{(8)}$.

A questão norteadora do estudo foi elaborada com base na estratégia Population, Variables and Outcomes (PVO), que vislumbra o encontro das respostas adequadas às perguntas da pesquisa, com vistas a melhor compreensão dos aspectos sociais, do contexto e de suas variáveis, conforme exemplificado no Quadro 1.

Quadro 1 - Elaboração da pergunta norteadora baseada na estratégia Population, Variables and Outcomes. Juazeiro do Norte, Ceará, Brasil - 2020

\begin{tabular}{|l|l|l|l|}
\hline $\begin{array}{l}\text { Itens da } \\
\text { Estratégia }\end{array}$ & \multicolumn{1}{|c|}{ Componentes } & $\begin{array}{l}\text { Descritores em Ciências } \\
\text { da Saúde (DeCS) }\end{array}$ & $\begin{array}{l}\text { Medical Subject } \\
\text { Headings (MeSH) }\end{array}$ \\
\hline Population & Profissionais de enfermagem & Enfermagem & Nursing \\
\hline Variables & Assistência em hemodiálise & Hemodiálise & Renal Dialysis \\
\hline Variables & Acidentes de trabalho & Riscos Ocupacionais & Occupational Risks \\
\hline Variables & Prevenção de agravos a saúde & Prevenção de Acidentes & Accident Prevention \\
\hline Outcomes & Biossegurança & $\begin{array}{l}\text { Contenção de Riscos } \\
\text { Biológicos }\end{array}$ & $\begin{array}{l}\text { Containment of } \\
\text { Biobazards }\end{array}$ \\
\hline
\end{tabular}

Fonte: Elaboração própria.

Após a utilização da estratégia PVO, a questão norteadora do estudo consistiu em: Qual o conhecimento dos profissionais de enfermagem acerca das medidas de biossegurança na prevenção de agravos à saúde durante a assistência em hemodiálise?
A busca dos artigos foi realizada por dois pesquisadores, de maneira independente, no período de abril a maio de 2020, nas bases de dados da Literatura Latino-Americana e do Caribe em Ciências da Saúde (LILACS) e na Base de Dados em Enfermagem (BDENF), bem como 
no diretório de revistas da Scientific Electronic Library Online (SciELO), por meio do cruzamento dos Descritores em Ciências da Saúde (DeCS) e dos Medical Subject Headings (MeSH): Enfermagem (Nursing), Hemodiálise (Renal Dialysis), Riscos Ocupacionais (Occupational Risks), Prevenção de Acidentes (Accident Prevention), Contenção de Riscos Biológicos (Containment of Biohazards), com a utilização do operador booleano $A N D$.

Definiram-se como critérios de inclusão: estudos disponíveis na íntegra, do tipo artigo científico primário, publicados entre os anos de 2010 e 2020, nos idiomas inglês, português e espanhol. Adotou-se como critérios de exclusão estudos duplicados nas bases de dados, que não se adequavam ao tema proposto e/ou não respondiam à questão do estudo, artigos de revisão, dissertação e teses, identificados após leitura do título e resumo na íntegra.

Foram identificados 691 estudos, e depois de aplicados os critérios de inclusão e exclusão, a amostra final desta revisão foi composta por 12 artigos, conforme elucidado na Figura 1.

Para favorecer a extração das informações significativas dos estudos, foi elaborado um banco de dados no programa Microsoft Office Word (versão 2019), no qual foram realizados a codificação, o fichamento e a categorização dos estudos, com base na síntese dos artigos incluídos na revisão integrativa, de acordo com o título, autores, ano de publicação, base de dados, revista/periódico e principais resultados. Cabe destacar que foi utilizado o checklist Preferred Reporting Items for Systematic Reviews and Meta-Analyses (PRISMA) nos itens em que este era aplicável.

Em respeito aos aspectos éticos e legais, ressalta-se que este estudo não foi submetido ao Comitê de Ética em Pesquisa, visto que o seu perfil científico (revisão integrativa) dispensa a avaliação ética, nos termos da Resolução n. 466/2012. No entanto, no que cabe aos princípios de autoria, toda a literatura utilizada para a construção do artigo foi devidamente citada e referenciada.

Figura 1 - Fluxograma da seleção dos estudos de acordo com o Preferred Reporting Items for Systematic Reviews and Meta-Analyses

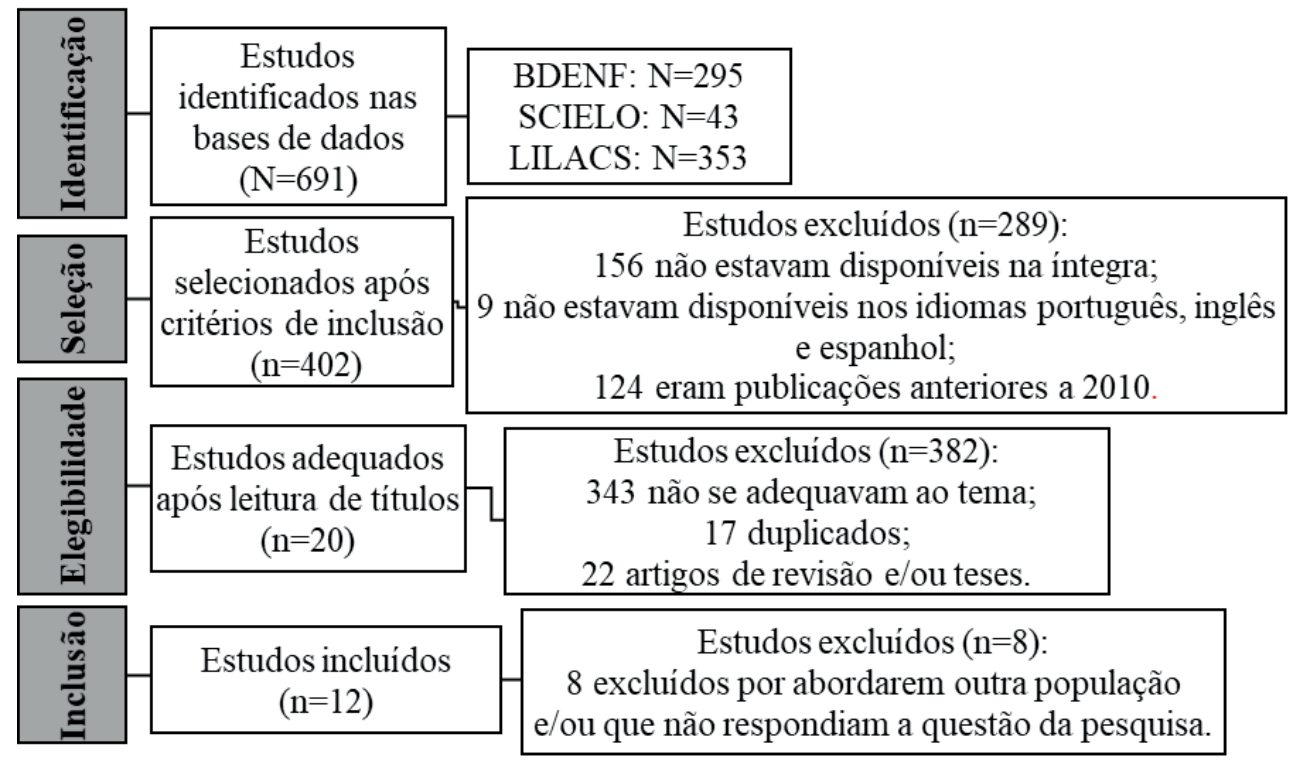

Fonte: Elaboração própria.

\section{Resultados}

Após a estratégia de busca dos artigos, identificação, seleção, elegibilidade e inclusão, obteve-se um total de 12 estudos que sintetizaram os principais achados acerca das medidas de biossegurança na assistência de enfermagem a pacientes hemodialíticos, conforme exposto no Quadro 2. 
Quadro 2 - Síntese dos artigos incluídos na revisão integrativa. Juazeiro do Norte, Ceará, Brasil -2020

\begin{tabular}{|c|c|c|c|c|}
\hline Título do artigo & Autores / ano & $\begin{array}{c}\text { Base de } \\
\text { dados }\end{array}$ & $\begin{array}{c}\text { Revista / } \\
\text { Periódicos }\end{array}$ & Principais resultados \\
\hline $\begin{array}{l}\text { Representações } \\
\text { sociais da } \\
\text { Enfermagem } \\
\text { sobre } \\
\text { biossegurança: } \\
\text { saúde } \\
\text { ocupacional } \\
\text { e o cuidar } \\
\text { prevencionista }\end{array}$ & $\begin{array}{l}\text { Sousa AFL, } \\
\text { Queiroz AAFLN, } \\
\text { Oliveira LB, } \\
\text { Moura MEB, } \\
\text { Batista OMA, } \\
\text { Andrade D, } \\
2016^{(3)}\end{array}$ & BDENF & $\begin{array}{l}\text { Revista } \\
\text { Brasileira de } \\
\text { Enfermagem }\end{array}$ & $\begin{array}{l}\text { Os profissionais possuem dificuldade } \\
\text { em convergir formação e atuação com } \\
\text { o discurso e a prática, representados } \\
\text { pela não utilização dos Equipamentos } \\
\text { de Proteção Individual (EPIs), quando } \\
\text { necessário. Percebe-se que o uso dos } \\
\text { EPIs parece uma atividade apenas } \\
\text { teórica, que não possui espaço em } \\
\text { sua rotina de trabalho, ainda que seja } \\
\text { largamente indicado para precauções } \\
\text { padrões. Os resultados dessa pesquisa } \\
\text { indicaram que os participantes } \\
\text { compreendem a biossegurança como } \\
\text { atividades que remetem a maior } \\
\text { ou menor risco, destacando como } \\
\text { preocupante principalmente aquelas } \\
\text { doenças com transmissão por aerossóis. }\end{array}$ \\
\hline $\begin{array}{l}\text { Riscos } \\
\text { ocupacionais } \\
\text { enfrentados pelo } \\
\text { trabalhador de } \\
\text { enfermagem } \\
\text { no setor de } \\
\text { hemodiálise }\end{array}$ & $\begin{array}{l}\text { Correa RA, } \\
\text { Souza NVDO, } \\
2012^{(9)}\end{array}$ & BDENF & $\begin{array}{l}\text { Revista de } \\
\text { Pesquisa } \\
\text { Cuidado é } \\
\text { Fundamental } \\
\text { Online }\end{array}$ & $\begin{array}{l}\text { Os trabalhadores julgaram o tempo } \\
\text { de serviço no setor, a autoconfiança, } \\
\text { a experiência e a resistência como } \\
\text { fatores que dificultam a utilização do } \\
\text { EPI por parte dos profissionais de } \\
\text { enfermagem do setor de hemodiálise. } \\
\text { Assim, os trabalhadores não acreditam } \\
\text { na contaminação do material que } \\
\text { manipulam, ficando expostos aos } \\
\text { riscos ocupacionais presentes no } \\
\text { referido setor. A baixa adesão aos } \\
\text { EPIs foi referida pela maioria dos } \\
\text { profissionais de enfermagem. }\end{array}$ \\
\hline $\begin{array}{l}\text { A unidade } \\
\text { dialítica como } \\
\text { um cenário de } \\
\text { exposição a } \\
\text { riscos }\end{array}$ & $\begin{array}{l}\text { Morais EM, } \\
\text { Fontana RT, } \\
2014^{(10)}\end{array}$ & LILACS & $\begin{array}{l}\text { Revista de } \\
\text { Pesquisa } \\
\text { Cuidado é } \\
\text { Fundamental } \\
\text { Online }\end{array}$ & $\begin{array}{l}\text { Os riscos ocupacionais mais } \\
\text { referenciados foram os biológicos, } \\
\text { químicos, físicos e ergonômicos, e, } \\
\text { com menor frequência, o psicossocial. } \\
\text { As estratégias apontadas para redução } \\
\text { dos riscos envolvem o uso de EPI, } \\
\text { cuidados com a postura corporal } \\
\text { e a disponibilização de mobiliário } \\
\text { adequado por parte da instituição. }\end{array}$ \\
\hline $\begin{array}{l}\text { Riscos } \\
\text { ocupacionais no } \\
\text { processamento } \\
\text { de sistemas de } \\
\text { hemodiálise }\end{array}$ & $\begin{array}{l}\text { Hoefel HHK, } \\
\text { Lautert L, } \\
\text { Fortes C, } \\
2012^{(11)}\end{array}$ & BDENF & $\begin{array}{l}\text { Revista } \\
\text { Eletrônica de } \\
\text { Enfermagem }\end{array}$ & $\begin{array}{l}\text { Os profissionais higienizaram suas } \\
\text { mãos após todos os } 36 \text { (100\%) } \\
\text { procedimentos para tratamento } \\
\text { de filtros de hemodiálise. Nesse } \\
\text { momento, falharam em } 6(17 \%) \\
\text { ocasiões na técnica asséptica, } \\
\text { contaminando as superfícies com } \\
\text { as luvas usadas. Embora sempre } \\
\text { tenha sido utilizado algum tipo } \\
\text { de EPI, o uso foi incompleto, por } \\
\text { exemplo, proteção com óculos de } \\
\text { uso pessoal, quando seria ideal um } \\
\text { protetor que cobrisse uma superfície } \\
\text { maior ao redor dos olhos, conforme } \\
\text { recomendações internacionais. }\end{array}$ \\
\hline
\end{tabular}


Quadro 2 - Síntese dos artigos incluídos na revisão integrativa. Juazeiro do Norte, Ceará, Brasil -2020

\begin{tabular}{|c|c|c|c|c|}
\hline Título do artigo & Autores / ano & $\begin{array}{c}\text { Base de } \\
\text { dados }\end{array}$ & $\begin{array}{c}\text { Revista / } \\
\text { Periódicos }\end{array}$ & Principais resultados \\
\hline $\begin{array}{l}\text { Conhecimentos } \\
\text { de enfermeiros } \\
\text { sobre acidentes } \\
\text { de trabalho }\end{array}$ & $\begin{array}{l}\text { Melo FMS, } \\
\text { Oliveira BSB, } \\
\text { Oliveira RKL, } \\
\text { Bezerra JC, } \\
\text { Silva MJN, } \\
\text { Joventino ES, } \\
2017^{(12)}\end{array}$ & LILACS & Revista Rene & $\begin{array}{l}\text { Foi averiguado no estudo que os } \\
\text { profissionais detêm conhecimentos } \\
\text { sobre prevenção e medidas pós- } \\
\text {-exposição a material biológico. } \\
\text { Os dez entrevistados informaram o } \\
\text { uso frequente dos EPIs e o descarte } \\
\text { de material perfurocortante em local } \\
\text { adequado. No entanto, nenhum } \\
\text { dos enfermeiros entrevistados citou, } \\
\text { entre os cuidados pós-exposição, o } \\
\text { uso do álcool em gel a 70\% para a } \\
\text { antissepsia das mãos, devendo essa } \\
\text { prática ser rotina independentemente } \\
\text { da ocorrência. }\end{array}$ \\
\hline $\begin{array}{l}\text { Significados } \\
\text { contextuais } \\
\text { e o acidente } \\
\text { perfurocortante: } \\
\text { repercussões } \\
\text { para o cuidado } \\
\text { de enfermagem }\end{array}$ & $\begin{array}{l}\text { Rosa LS, } \\
\text { Valadares GV, } \\
\text { Pedreira QDM, } \\
\text { Ribeiro LR, } \\
2018^{(13)}\end{array}$ & LILACS & $\begin{array}{l}\text { Revista } \\
\text { Enfermagem } \\
\text { UERJ }\end{array}$ & $\begin{array}{l}\text { A experiência profissional e o } \\
\text { respeito às normas de biossegurança } \\
\text { podem minimizar a exposição a } \\
\text { riscos. O despreparo do profissional, } \\
\text { expresso pelo desconhecimento } \\
\text { do uso correto das recomendações } \\
\text { padrão e pela falta de habilidade } \\
\text { em realizar os procedimentos, pode } \\
\text { facilitar a ocorrência de acidente com } \\
\text { materiais perfurocortantes. A falta de } \\
\text { capacitação profissional colabora para } \\
\text { a vulnerabilidade do profissional. }\end{array}$ \\
\hline $\begin{array}{l}\text { A aplicação da } \\
\text { precaução e da } \\
\text { prevenção no } \\
\text { ambiente de } \\
\text { trabalho }\end{array}$ & $\begin{array}{l}\text { Carvalho EC, } \\
\text { David HMSL, } \\
2016^{(14)}\end{array}$ & BDENF & $\begin{array}{l}\text { Revista } \\
\text { Enfermagem } \\
\text { UERJ }\end{array}$ & $\begin{array}{l}\text { A prevenção diz respeito a riscos } \\
\text { certos e comprovados (perigo). } \\
\text { A precaução se liga a riscos } \\
\text { simplesmente potenciais. Na } \\
\text { prevenção, a periculosidade já se } \\
\text { encontra estabelecida, o perigo é } \\
\text { concreto. Na precaução, ao contrário, } \\
\text { tem-se um perigo abstrato (risco), } \\
\text { em virtude da imprecisão dos } \\
\text { conhecimentos científicos, incapazes } \\
\text { de mensurar o dano, ou mesmo de } \\
\text { fornecer certeza quanto à ocorrência, } \\
\text { atual ou superveniente de danos. }\end{array}$ \\
\hline $\begin{array}{l}\text { Medidas } \\
\text { preventivas } \\
\text { nas práticas } \\
\text { de inserção e } \\
\text { manipulação } \\
\text { de cateter de } \\
\text { hemodiálise: } \\
\text { estudo } \\
\text { observacional }\end{array}$ & $\begin{array}{l}\text { Duarte TAC, } \\
\text { Alencar TD, } \\
\text { Custódio N, } \\
2017^{(15)}\end{array}$ & BDENF & $\begin{array}{l}\text { Revista } \\
\text { Enfermagem } \\
\text { Atual In } \\
\text { Derme }\end{array}$ & $\begin{array}{l}\text { No estudo totalizaram 94\% }(n=58) \text { de } \\
\text { práticas de higienização das mãos } \\
\text { em não conformidade na pré e } 82 \% \\
(n=47) \text { na pós-manipulação do cateter } \\
\text { de hemodiálise. }\end{array}$ \\
\hline
\end{tabular}


Quadro 2 - Síntese dos artigos incluídos na revisão integrativa. Juazeiro do Norte, Ceará, Brasil -2020

\begin{tabular}{|c|c|c|c|c|}
\hline Título do artigo & Autores / ano & $\begin{array}{c}\text { Base de } \\
\text { dados }\end{array}$ & $\begin{array}{c}\text { Revista / } \\
\text { Periódicos }\end{array}$ & Principais resultados \\
\hline $\begin{array}{l}\text { Acidentes } \\
\text { de trabalho } \\
\text { com material } \\
\text { biológico na } \\
\text { equipe de } \\
\text { enfermagem de } \\
\text { um hospital do } \\
\text { Centro-Oeste } \\
\text { brasileiro }\end{array}$ & $\begin{array}{l}\text { Carvalho DC, } \\
\text { Rocha JC, } \\
\text { Gimenes MCA, } \\
\text { Santos EC, } \\
\text { Valim MD, } \\
2018^{(16)}\end{array}$ & BDENF & $\begin{array}{l}\text { Escola Anna } \\
\text { Nery }\end{array}$ & $\begin{array}{l}\text { A pesquisa mostra que apenas } 42,6 \% \\
\text { dos profissionais participaram de } \\
\text { treinamentos sobre as precauções } \\
\text { padrão, no ano de } 2016 . \text { No período } \\
\text { de } 2008 \text { a } 2015 \text {, obteve-se um total } \\
\text { de } 36 \text { profissionais que receberam } \\
\text { capacitação ( } 57,1 \%) \text { e } 15 \text { ( } 23,8 \%) \\
\text { profissionais que não responderam } \\
\text { a essa informação. Apenas } 64,9 \% \\
\text { dos trabalhadores realizavam a } \\
\text { troca do recipiente de descarte de } \\
\text { material perfurocortante quando } \\
\text { atingido } 2 / 3 \text { de preenchimento. } \\
\text { Com relação ao uso de EPI, } \\
\text { apenas } 95 \text { trabalhadores (64,2\%) } \\
\text { afirmaram utilizar sapatos fechados, } \\
\text { impermeáveis e antiderrapantes, } \\
\text { conforme normatização da NR-32. } \\
\text { Dez profissionais (6,8\%) alegaram } \\
\text { não ter recebido o esquema vacinal } \\
\text { adequado e completo para Hepatite } \\
\text { B. Da mesma forma, } 19 \text { profissionais } \\
\text { (12,8\%) relataram que desconhecem a } \\
\text { sua resposta vacinal, isto é, ignoram } \\
\text { se estão realmente imunizados com } \\
\text { o anticorpo anti-Hepatite B, ao passo } \\
\text { que } 92 \text { ( } 71,3 \% \text { ) dos trabalhadores } \\
\text { afirmaram que o resultado do exame } \\
\text { foi negativo. }\end{array}$ \\
\hline $\begin{array}{l}\text { Conformidade } \\
\text { de higiene } \\
\text { das mãos na } \\
\text { manutenção } \\
\text { do cateter para } \\
\text { hemodiálise }\end{array}$ & $\begin{array}{l}\text { Rosetti KAG, } \\
\text { Tronchin DMR, } \\
2015^{(17)}\end{array}$ & SciELO & $\begin{array}{l}\text { Revista } \\
\text { Brasileira de } \\
\text { Enfermagem }\end{array}$ & $\begin{array}{l}\text { Verificou-se que em } 1.902 \\
\text { oportunidades de higiene das mãos } \\
\text { houve } 35,6 \% \text { de adesão à prática } \\
\text { após o contato com o paciente, e } \\
\text { apenas } 13,8 \% \text { antes do contato } \\
\text { com o paciente. A maioria dos } \\
\text { resultados aponta a baixa adesão } \\
\text { dos profissionais de saúde, o que se } \\
\text { configura como um grande desafio } \\
\text { na prevenção e no controle das } \\
\text { infecções relacionadas à assistência } \\
\text { em saúde. }\end{array}$ \\
\hline $\begin{array}{l}\text { Inserção de } \\
\text { cateter vascular } \\
\text { central: adesão } \\
\text { a bundle de } \\
\text { prevenção de } \\
\text { infecção }\end{array}$ & $\begin{array}{l}\text { Llapa- } \\
\text {-Rodríguez EO, } \\
\text { Oliveira JKA, } \\
\text { Melo FC, } \\
\text { Silva GG, } \\
\text { Mattos MCT, } \\
\text { Macieira Jr VP, } \\
2019^{(18)}\end{array}$ & SciELO & $\begin{array}{l}\text { Revista } \\
\text { Brasileira de } \\
\text { Enfermagem }\end{array}$ & $\begin{array}{l}\text { Os resultados afirmam que os } \\
\text { instrumentos de verificação de } \\
\text { processos assistenciais apresentam } \\
\text { melhor adesão quando há } \\
\text { aprimoramento do processo de } \\
\text { trabalho, sensibilização da equipe na } \\
\text { implementação, responsabilização } \\
\text { pela aplicação do instrumento e } \\
\text { avaliação contínua quanto à adesão } \\
\text { ao checklist. }\end{array}$ \\
\hline
\end{tabular}


Quadro 2 - Síntese dos artigos incluídos na revisão integrativa. Juazeiro do Norte, Ceará, Brasil -2020

\begin{tabular}{|c|c|c|c|c|}
\hline Título do artigo & Autores / ano & $\begin{array}{c}\text { Base de } \\
\text { dados }\end{array}$ & $\begin{array}{c}\text { Revista / } \\
\text { Periódicos }\end{array}$ & Principais resultados \\
\hline $\begin{array}{l}\text { Avaliação da } \\
\text { conformidade } \\
\text { da prática } \\
\text { assistencial de } \\
\text { manutenção } \\
\text { do cateter } \\
\text { temporário } \\
\text { duplo lúmen } \\
\text { para hemodiálise }\end{array}$ & $\begin{array}{l}\text { Rosetti KAG, } \\
\text { Tronchin DMR, } \\
2014^{(19)}\end{array}$ & SciELO & \begin{tabular}{|l} 
Revista \\
Latino- \\
-Americana de \\
Enfermagem
\end{tabular} & $\begin{array}{l}\text { Em relação ao uso de máscara, } \\
\text { os resultados mostraram que sua } \\
\text { utilização pelo profissional na } \\
\text { conexão e na desconexão do serviço } \\
\text { de hemodiálise foi atendida na maioria } \\
\text { das oportunidades de avaliação, sendo } \\
\text { 99,4\% em conformidade na conexão } \\
\text { e 100\% na desconexão. Neste estudo } \\
\text { constatou-se que, no componente } \\
\text { de higienização das mãos, apesar } \\
\text { do predomínio da conformidade } \\
\text { (130-83,9\%), número considerável } \\
\text { de oportunidades apresentou-se não } \\
\text { conforme (25-16,1\%), demonstrando a } \\
\text { fragilidade na adesão à prática. }\end{array}$ \\
\hline
\end{tabular}

Fonte: Elaboração própria.

Os resultados desta pesquisa fundamentaram-se na avaliação minuciosa dos estudos selecionados e posterior realização de análise comparativa dos estudos frente ao objeto de pesquisa proposto. Assim, foi avaliado o conhecimento dos profissionais de enfermagem acerca das medidas básicas de biossegurança na assistência de enfermagem a pacientes hemodialíticos, as implicações dessa prática e as lacunas do conhecimento.

\section{Discussão}

Diante da construção do estudo por meio dos artigos selecionados e analisados, foram averiguadas as principais medidas relacionadas à biossegurança e os fatores contribuintes e/ou dificultadores para o não seguimento aos seus preceitos básicos, o que pode representar riscos à saúde dos profissionais durante o desenvolvimento de suas atividades laborais.

Assim, após a análise dos dados, foram elencadas as principais barreiras para a execução das medidas de biossegurança, tais como déficit de aplicação do conhecimento teórico na prática laboral, falta de capacitação do pessoal mediante educação continuada e a própria negligência por parte de alguns profissionais, o que pode promover o desenvolvimento de acidentes ocupacionais nos ambientes assistenciais.
Nesse contexto, com a finalidade de favorecer melhor compreensão acerca dos resultados obtidos no estudo, optou-se pela fragmentação da discussão dos dados em duas categorias, a saber: "A biossegurança no ambiente de hemodiálise" e as "Dificuldades para implementação das medidas de biossegurança”.

\section{A biossegurança no ambiente de hemodiálise}

Evidenciou-se que os profissionais de enfermagem compreendem a necessidade da biossegurança, assim como detêm conhecimento sobre a temática, seu objetivo e seus aspectos. Entretanto, foi observado que esse mesmo conhecimento não tem sido colocado em sua totalidade na prática, haja vista as falhas mencionadas nos estudos, antes, durante e/ou após a implementação da assistência, em decorrência de fatores como: falta de estrutura adequada do estabelecimento, carência de materiais e equipamentos e a própria negligência do profissional.

Não obstante alguns profissionais seguirem as normas orientadas pela NR-32 $2^{(5)}$, os estudos afirmam que é evidente a violação, por parte de alguns indivíduos, das medidas de biossegurança, seja por opção própria ou por outros motivos, tais como: falta de EPIs adequados para a realização de procedimentos e/ou para setores específicos; treinamento inadequado 
e/ou inexistente quanto à utilização dos EPIs; falta de estruturas adequadas nos estabelecimentos para a correta higienização das mãos; e cartão de vacinação desatualizado.

Averiguou-se que, na maioria dos estudos, dentre as práticas de biossegurança, a considerada mais simples e que detém maior aplicabilidade no ambiente laboral é a higienização das mãos, e que os profissionais de saúde detêm conhecimento de que a utilização de água e sabão contribui para a prevenção de infecções.

Estudos evidenciam que a aplicação das medidas de biossegurança nos ambientes de saúde é tida como uma maneira de promover a atenuação de riscos, medida esta que deve ser recomendada e incentivada pelas instituições mantenedoras, e empregada pelos profissionais, com a finalidade de minimizar e/ou eliminar os riscos de contaminação, sendo esta uma prática essencial no ambiente de hemodiálise ${ }^{(20)}$.

Corroborando os achados desta pesquisa, suscita-se que o setor de hemodiálise é tido como um ambiente com grande potencial de risco de acidentes, pois os profissionais encontram-se constantemente expostos a riscos de contaminação, dentre os quais podemos citar: o contato com secreções, fluidos corporais e sangue, seja durante a punção da fístula arteriovenosa, manipulação de cateteres e/ou de materiais perfurocortantes ${ }^{(6)}$.

O emprego dos dispositivos de biossegurança inicia-se com a adoção das medidas consideradas básicas, denominadas precauções padrão, sendo elas: a higienização das mãos, o uso de EPIs e Equipamentos de Proteção Coletiva (EPCs), o manejo adequado de resíduos dos serviços de saúde e a imunização dos profissionais de saúde ${ }^{(21)}$.

Para a organização e implementação das práticas de biossegurança, elenca-se como um de seus principais elementos o gerenciamento adequado dos resíduos produzidos pelos serviços de saúde, haja vista que estes estabelecimentos são responsáveis desde a sua geração até o seu destino final. A implementação de um sistema de gerenciamento dos resíduos nos serviços de saúde possibilita a redução de riscos, a execução de trabalho com segurança, o manuseio cuidadoso, o armazenamento, o transporte seguro dos materiais perfurocortantes e o seu descarte em local apropriado, ações estas que podem favorecer a minimização do risco de acidentes de trabalho e a menor exposição a materiais biológicos $^{(21-22)}$.

Ao encontro dos achados deste estudo, pesquisa realizada no Hospital das Clínicas Dr. Alberto Lima, no estado do Amapá, afirma que o descarte de materiais perfurocortantes em local inadequado pode contribuir para a ocorrência de acidentes, sendo um dos principais fatores causais de risco ocupacional para os profissionais de saúde, destacando-se ainda o reencape de agulhas como responsável por uma margem considerável de acidentes ${ }^{(22)}$.

No entanto, estudos contemporâneos afirmam que, apesar de deterem conhecimento quanto às práticas de biossegurança, os profissionais não aplicam à práxis, haja vista a existência de erros na realização da técnica correta de higienização das mãos nos cinco momentos preconizados pela Organização Mundial da Saúde (OMS) ${ }^{(23)}$.

Nesse contexto, a Agência Nacional de Vigilância Sanitária (Anvisa) descreve a higiene das mãos como uma das principais estratégias de prevenção de infecções, devendo esta ser executada por todos os profissionais da saúde no âmbito laboral, nos cinco momentos preconizados pela OMS, a saber: antes de tocar o paciente, antes de realizar procedimento limpo/asséptico, após risco de exposição a fluidos corporais, após tocar o paciente e após tocar superfícies próximas ao paciente ${ }^{(24)}$.

Ressalta-se, ainda, que pode ser realizada como técnica de higiene das mãos a fricção alcoólica com álcool a 70\%, desde que estas não estejam visivelmente sujas, devendo ter duração entre 20 e 30 segundos. Essa prática é altamente eficaz, desde que executada nos cinco momentos preconizados, para diminuição e/ou eliminação de crescimento microbiano ${ }^{(24)}$.

Em relação ao uso de luvas, evidenciou-se neste estudo que ocorre sua utilização de forma parcial, mesmo sendo recomendada com a finalidade de evitar a probabilidade de contato 
do profissional com fluidos corporais, secreções e/ou pele não íntegra. Nesse contexto, destaca-se ainda que o uso da máscara e óculos de proteção também são recomendados para evitar a contaminação por aerossóis. No entanto, resultados semelhantes a este estudo são mencionados em uma pesquisa sobre a assistência de enfermagem ao portador de doença renal crônica com infecção na fístula, na qual se evidenciou a baixa utilização dos EPIs supracitados ${ }^{(25)}$.

A adesão de atitudes proativas para a promoção das medidas de biossegurança por parte dos profissionais contribui substancialmente para a prevenção de acidentes no âmbito da saúde, o que favorece a manutenção da segurança do profissional e dos pacientes, mediante a aplicação das normas técnicas e do seu conhecimento quanto aos riscos aos quais estão expostos durante suas atividades assistenciais ${ }^{(26)}$.

Em meio a estudos contemporâneos, evidenciou-se, ainda, que, o uso do EPI é a principal forma de promover a redução dos riscos permanentes de exposição dos profissionais da saúde a doenças transmissíveis, principalmente as decorrentes do contato com sangue e/ou fluidos corporais ${ }^{(26)}$.

Contudo, não obstante as recomendações de uso e da ciência dos profissionais sobre a importância dos EPIs, foram encontradas algumas lacunas no conhecimento quanto a não adesão destes durante a assistência a pacientes hemodialíticos, seja por falta desses instrumentos em algumas unidades de saúde, por não adequação dos EPIs ao ambiente laboral e/ou pela própria negligência do profissional quanto ao seu uso ${ }^{(27)}$.

\section{Dificuldades para implementação das medidas de biossegurança}

Frente aos achados do estudo averiguou-se que algumas pesquisas apresentaram as principais causas que dificultam o emprego das medidas de biossegurança, tais como: falta de EPIs e atualizações de uso por meio de treinamentos; estruturas de estabelecimentos fora dos padrões corretos; aspectos intrínsecos dos próprios profissionais, que, comumente, negligenciam o uso de precauções, devido ao longo período de trabalho no setor, o que culmina na diminuição do medo de se contaminar; e o não descarte correto dos materiais perfurocortantes.

Aspectos estes que, em suma, são responsáveis pela não observância dos profissionais de enfermagem atuantes em centros de hemodiálise aos princípios básicos de biossegurança, o que evidencia a necessidade dessa temática ser continuamente discutida, analisada e trabalhada nos ambientes laborais.

$\mathrm{Na}$ prestação dos cuidados de enfermagem pode ocorrer, em alguns casos, negligência dos profissionais quanto às normas de biossegurança, como, por exemplo, a não utilização dos EPIs, sendo estes mais utilizados na assistência aos pacientes, cujo diagnóstico é conhecido, subestimando-se a vulnerabilidade do organismo humano às infecções. Recomenda-se, dessa forma, que os profissionais da saúde utilizem todos os EPIs durante o desenvolvimento de suas atividades assistenciais, com ou sem riscos de contato com materiais biológicos ${ }^{(28)}$.

Inferem-se como fatores promotores da baixa adesão dos profissionais às medidas de biossegurança nas unidades de saúde: a não realização de atualizações sobre o tema, mediante educação continuada; a negligência aliada ao desconhecimento sobre biossegurança; a confiança excessiva na sua capacidade prática; a baixa percepção que os profissionais têm acerca dos riscos aos quais estão expostos e sua susceptibilidade; e o seu descrédito quanto aos EPIs ${ }^{(29)}$.

Assim, diante dos achados da pesquisa, foram encontrados fatores que atuam como barreiras para a utilização das medidas de biossegurança nas instituições de hemodiálise, dentre os quais podemos citar: o tempo de serviço no setor, a autoconfiança excessiva, a experiência e a resistência dos profissionais às medidas de educação continuada. Ações estas que inibem o emprego correto das medidas de biossegurança por parte dos profissionais de enfermagem atuantes nesses setores assistenciais ${ }^{(9)}$.

Este aspecto culmina na expressão de um elevado risco de exposição dos profissionais a acidentes ocupacionais nesses setores, haja 
vista não acreditarem no risco de contaminação pelos materiais biológicos, fluidos, secreções e perfurocortantes, que estão em contato intrínseco diariamente ${ }^{(9)}$.

Corroborando também ao evidenciado nos estudos, dentre os desafios vivenciados para a execução dos princípios básicos de biossegurança, destacam-se a não adequação entre teoria e prática, falta de materiais adequados e o relaxamento de alguns profissionais com relação ao seu autocuidado, não seguindo ou não executando as devidas medidas de prevenção ${ }^{(30)}$.

$\mathrm{Na}$ análise dos dados da pesquisa evidenciou-se que medidas relativamente simples de serem executadas, tais como a higienização das mãos e/ou fricção com solução alcoólica e a utilização de EPIs durante as atividades laborativas, exercem papel fundamental para a atenuação de riscos. Essas medidas devem ser incentivadas pelos estabelecimentos de saúde e empregadas corretamente pelos seus profissionais, vislumbrando, assim, a eliminação e/ou atenuação dos riscos advindos das práticas assistenciais.

Tem-se como limitações do estudo a quantidade limitada de artigos científicos primários publicados acerca do conhecimento dos profissionais de enfermagem sobre o tema; a inclusão de estudos somente nos idiomas português, inglês e espanhol, não abrangendo pesquisas publicadas em outros idiomas, bem como não terem sido utilizadas dissertações e teses na discussão dos resultados. Assim, sugere-se a realização de novos estudos primários, com a finalidade de compreender, de maneira mais ampla, o conhecimento e a adesão dos profissionais de enfermagem atuantes em serviços de hemodiálise, acerca das medidas de contenção de riscos biológicos.

\section{Conclusão}

Os profissionais de enfermagem detêm conhecimento acerca das medidas de biossegurança e reconhecem a necessidade da sua aplicação como instrumento efetivo no desempenho das suas atividades laborais em ambientes de hemodiálise, adotando e recomendando a sua utilização. No entanto, não obstante conhecerem a necessidade da biossegurança nesses ambientes assistenciais, averiguou-se que existem lacunas do conhecimento entre o discurso e a prática assistencial.

Desse modo, evidenciou-se que, dentre as práticas de biossegurança mais implementadas pelos profissionais de enfermagem nos serviços de hemodiálise podemos citar a higienização das mãos com água e sabão, o descarte correto de objetos perfurocortantes e o uso de EPIs, sendo mais frequente o uso isolado da máscara de proteção e luvas de procedimento.

Verificou-se, ainda, as principais barreiras para o não seguimento dos profissionais às medidas de biossegurança, dentre as quais se destacaram: o tempo de atuação no serviço e/ou setor, a autoconfiança excessiva, a experiência profissional e a resistência dos profissionais quanto ao uso correto de EPIs.

Desse modo, para a promoção e o empoderamento dos profissionais de enfermagem quanto às medidas de biossegurança, as instituições de saúde que atuam na realização do tratamento renal substitutivo, hemodiálise, devem promover o desenvolvimento de estratégias educativas que relacionem essas medidas com a necessidade de um acompanhamento qualificado, a fim de favorecer o esclarecimento das principais indagações dos profissionais para melhor desenvolvimento de métodos preventivos e incentivo à promoção de seus conhecimentos específicos.

Por meio deste estudo, evidenciou-se que a temática de biossegurança, embora seja relatada em estudos, detém uma amplitude reduzida, devendo ser constantemente discutida e trabalhada com os profissionais de enfermagem atuantes na hemodiálise. Além disso, salienta-se a necessidade de maior engajamento dos gestores das instituições de saúde na implantação, manutenção e educação, com a finalidade de promover melhores condições laborais para a promoção da segurança, com vistas à eliminação e/ou atenuação de riscos nas atividades laborais.

A realização deste estudo possibilitou compreender o nível de conhecimento dos profissionais de enfermagem atuantes em hemodiálise 
acerca das medidas de biossegurança como método preventivo de acidentes biológicos nos ambientes laborais. Aspectos estes, que podem favorecer o desenvolvimento de medidas de aprimoramento profissional, para minimização de riscos ocupacionais e fundamentação da prática de enfermagem.

\section{Colaborações:}

1 - concepção, projeto, análise e interpretação dos dados: Gilberto dos Santos Dias de Souza, Hercules Pereira Coelho e Aline Morais Venancio de Alencar;

2 - redação do artigo e revisão crítica relevante do conteúdo intelectual: Gilberto dos Santos Dias de Souza, Hercules Pereira Coelho, Janayle Kéllen Duarte de Sales, Halana Cecília Vieira Pereira, Ana Maria Machado Borges e Aline Morais Venancio de Alencar;

3 - aprovação final da versão a ser publicada: Gilberto dos Santos Dias de Souza, Hercules Pereira Coelho, Janayle Kéllen Duarte de Sales, Halana Cecília Vieira Pereira, Ana Maria Machado Borges e Aline Morais Venancio de Alencar.

\section{Referências}

1. Santos BP, Oliveira VA, Soares MC, Schwartz E. Doença renal crônica: relação dos pacientes com a hemodiálise. ABCS Health Sci. 2017;42(1):8-14. DOI: http://dx.doi.org/10.7322/abcshs.v42i1.943

2. Brasil. Ministério da Saúde. Portaria № 3.415, de 22 de outubro de 2018. Dispõe sobre os critérios para a organização, funcionamento e financiamento do cuidado da pessoa com Doença Renal Crônica - DRC no âmbito do Sistema Único de Saúde - SUS [Internet]. Brasília (DF); 2018 [cited 2019 Sep 11]. Available from: http:// bvsms.saude.gov.br/bvs/saudelegis/gm/2018/ prt3415_24_10_2018.html

3. Sousa AFL, Queiroz AAFLN, Oliveira LB, Moura MEB, Batista OMA, Andrade D. Representações sociais da Enfermagem sobre biossegurança: saúde ocupacional e o cuidar prevencionista. Rev Bras Enferm. 2016;69(5):810-7. DOI: http://dx.doi.org/10.1590/0034-7167-2015-0114

4. Prestes FC, Beck CLC, Magnago TSBS, Silva RM, Tavares JP. Contexto de trabalho em um serviço de hemodiálise: avaliação dos trabalhadores de enfermagem. Texto contexto - enferm. 2015;24(3):637-45. DOI: https://doi. org/10.1590/0104-07072015000220014

5. Brasil. Ministério do Trabalho e Emprego. Portaria GM/MSE $\mathrm{n}^{-}$485, de 11 de novembro de 2005 [Internet]. Brasília (DF); 2005 [cited 2019 Mar 8]. Available from: https://www.gov.br/ trabalho-e-previdencia/pt-br/composicao/orgaosespecificos/secretaria-de-trabalho/inspecao/ seguranca-e-saude-no-trabalho/sst-portarias/2005/ portaria_485_aprova_nr_32.pdf

6. Hoefel HHK, Lautert L. Riscos e acidentes ocupacionais durante o reprocessamento de hemodialisadores. Rev Epidemiol Control Infect [Internet]. 2014 [cited 2019 Mar 7];4(2):159-64. Available from: https://www.redalyc.org/pdf/ 5704/570463831007.pdf

7. Mendes KDS, Silveira RCCP, Galvão CM. Uso de gerenciador de referências bibliográficas na seleção dos estudos primários em revisão integrativa. Texto contexto - enferm. 2019; 28:e20170204. DOI: https://dx.doi.org/10.1590/ 1980-265X-TCE-2017-0204

8. Souza MT, Silva MD, Carvalho R. Revisão integrativa: o que é e como fazer. Einstein. 2010;8(1 Pt 1):102-6. DOI: https://doi.org/10.1590/ s1679-45082010rw1134

9. Correa RA, Souza NVDO. Riscos ocupacionais enfrentados pelo trabalhador de enfermagem no setor de hemodiálise. R pesq: cuid fundam online [Internet]. 2012 [cited 2019 Feb 28];4(4):275564. Available from: http://www.seer.unirio.br/ cuidadofundamental/article/view/1973

10. Morais EM, Fontana RT. A unidade dialítica como um cenário de exposição a riscos. J res: fundam care online. 2014;6(2):539-49. DOI: 10.9789/2175-5361.2014v6n2p539

11. Hoefel HHK, Lautert L, Fortes C. Riscos ocupacionais no processamento de sistemas de hemodiálise. Rev Eletr Enf. 2012;14(2):286-95. DOI: https://doi.org/10.5216/ree.v14i2.12601

12. Melo FMS, Oliveira BSB, Oliveira RKL, Bezerra JC, Silva MJN, Joventino ES. Conhecimentos de enfermeiros sobre acidentes de trabalho. Rev Rene. 2017;18(2):173-80. DOI: https://doi.org/10.15253/2175-6783.2017000 200005

13. Rosa LS, Valadares GV, Pedreira QHDM, Ribeiro LR. Significados contextuais e o acidente 
perfurocortante: repercussões para o cuidado de enfermagem. Rev enferm UERJ. 2018;26:e33767. DOI: http://dx.doi.org/10.12957/reuerj.2018.33767

14. Carvalho EC, David HMSL. A aplicação da precaução e da prevenção no ambiente de trabalho. Rev enferm UERJ. 2016;24(3):e26180. DOI: http://dx.doi.org/10.12957/reuerj.2016.26180

15. Duarte TAC, Alencar TD, Custódio N. Medidas preventivas nas práticas de inserção e manipulação de cateter de hemodiálise: estudo observacional. Rev Enferm Atual In Derme 2017;81(19):70-5. DOI: https://doi.org/10.31011/ reaid-2017-v.81-n.19-art.323

16. Carvalho DC, Rocha JC, Gimenes MCA, Santos EC, Valim MD. Acidentes de trabalho com material biológico na equipe de enfermagem de um hospital do Centro-Oeste brasileiro. Esc Anna Nery. 2018;22(1):e20170140. DOI: 10.1590/2177-9465-EAN-2017-0140

17. Rosetti KAG, Tronchin DMR. Conformidade de higiene das mãos na manutenção do cateter para hemodiálise. Rev Bras Enferm. 2015;68(6):742-7. DOI: http://dx.doi.org/10.1590/ 0034-7167.2015680608i

18. Llapa-Rodríguez EO, Oliveira JKA, Melo FC, Silva GG, Mattos MCT, Macieira Jr VP. Inserção de cateter vascular central: adesão a bundle de prevenção de infecção. Rev Bras Enferm. 2019;72(3):774-9. DOI: http://dx.doi. org/10.1590/0034-7167-2018-0124

19. Rosetti KAG, Tronchin DMR. Avaliação da conformidade da prática assistencial de manutenção do cateter temporário duplo lúmen para hemodiálise. Rev Latino-Am Enfermagem. 2014;22(1):1-7. DOI: 10.1590/0104-1169.2959.2378

20. Ribeiro IP, Rodrigues AM, Silva IC, Santos JD. Riscos ocupacionais da equipe de enfermagem na hemodiálise. Rev Interd [Internet]. 2016 [cited 2019 Nov 25];9(1):143-52. Available from: https:// dialnet.unirioja.es/descarga/articulo/6771975.pdf

21. Angelim RCM, Abrão FMS, Brandão BMGM, Freire DA, Marques SC, Oliveira DC. Práticas de biossegurança de profissionais de saúde nos cuidados ao indivíduo com HIV. Rev Enferm UFSM. 2017;7(3):424-35. DOI: $10.5902 / 217976$ 9225677

22. Sousa RL, Menezes RAO, Souza MJC, Pantoja VJC, Barbosa FHF, Almeida MFC. Descarte adequado de perfurocortantes num hospital de Macapá - Brasil: um importante fator de prevenção de acidentes. Ciência Equatorial [Internet]. 2013 [cited 2019 Sep 15];3(1):69-81. Available from: https://periodicos.unifap.br/index. $\mathrm{php} /$ cienciaequatorial/article/view/813/571

23. Coelho HP, Santos IRA, Nascimento CM, Carvalho ABL, Simão CEM, Oliveira $\mathrm{OP}$, et al. Adesão da equipe de enfermagem à higienização das mãos na unidade de terapia intensiva neonatal. Rev Eletrônica Acervo Saúde. 2020;39(39):e2169. DOI: https://doi.org/10.25248/ reas.e2169.2020

24. Agência Nacional de Vigilância Sanitária. Nota técnica № 01/2018 GVIMS/GGTES/ANVISA. Orientações Gerais para Higiene das Mãos em Serviços de Saúde [Internet]. Brasília (DF); 2018 [cited 2018 Apr 15]. Available from: http:// portal.anvisa.gov.br/documents/33852/271858/ $\mathrm{NOTA}+\mathrm{T} \% \mathrm{C} 3 \% 89 \mathrm{CNICA}+\mathrm{N} \% \mathrm{C} 2 \% \mathrm{BA} 01-$ $2018+$ G V I M S - G G T E S - A N V I S A/ ef1b8e18-a36f-41ae-84c9-53860bc2513f

25. Oliveira LAM, Galvão MPSP, Martins LMS, Ximenes VL, Martins CR, Vasconcelos BP, et al. Assistência de enfermagem ao portador de doença renal crônica com infecção na fístula: um estudo literário. Braz J Surg Clin Res [Internet]. 2018 [cited 2019 Aug 8];23(1):106-11. Available from: https://www.mastereditora.com. br/periodico/20180606_083306.pdf

26. Ferreira WFS, Oliveira EM. Biossegurança em relação a adesão de equipamentos de proteção individual. Rev Univ Vale Rio Verde. 2019;17(1):1-9. DOI: http://dx.doi.org/10.5892/ruvrd.v17i1.4977

27. Silva RR, Bezerra ALD, Sousa MNA. O trabalho de enfermagem na hemodiálise: uma abordagem sobre os riscos ocupacionais. C\&D-Rev Eletrônica Fainor [Internet]. 2012 [cited 2019 Oct 8];5(1):101-13. Available from: https://www. researchgate.net/publication/318429198_O_ TRABALHO_DE_ENFERMAGEM _ N A HEMODIALISE_UMA_ABORDAGEM_SOBRE_OS_ RISCOS_OCUPACIONAIS

28. Gallas SR, Fontana RT. Biossegurança e a enfermagem nos cuidados clínicos: contribuições para a saúde do trabalhador. Rev Bras Enferm. 2010;63(5):786-92. DOI: http://dx.doi. org/10.1590/S0034-71672010000500015

29. Neves HCC, Souza ACS, Medeiros M, Munari DB, Ribeiro LCM, Tipple AFV. Segurança dos trabalhadores de enfermagem e fatores determinantes para adesão aos equipamentos de proteção individual. Rev 
Latino-Am Enfermagem. 2011;19(2):1-8. DOI: $\quad$ http://dx.doi.org/10.1590/S0104-11692011 000200018

30. Andrade GB, Weykamp JM, Cecagno D, Pedroso VSM, Medeiros AC, Siqueira HCH. Biossegurança: fatores de risco vivenciados pelo enfermeiro no contexto de seu trabalho.
R pesq cuid fundam online. 2018;10(2):565-71. DOI: http://dx.doi.org/10.9789/2175-5361. 2018. v10i2.565-571

Recebido: 31 de julho de 2020

Aprovado: 25 de maio de 2021

Publicado: 10 de fevereiro de 2022

A Revista Baiana de Enfermagem utiliza a Licença Creative Commons - Atribuição-NãoComercial 4.0 Internacional. https://creativecommons.org/licenses/by-nc/4.0/ Este artigo é de acesso aberto distribuído sob os termos da Licença Creative Commons (CC BY-NC). Esta licença permite que outros remixem, adaptem e criem a partir do seu trabalho para fins não comerciais. Embora os novos trabalhos tenham de lhe atribuir o devido crédito e não possam ser usados para fins comerciais, os usuários não têm de licenciar esses trabalhos derivados sob os mesmos termos. 